\title{
Adaptation Mechanism of Roots to Low and High Nitrogen Revealed by Proteomic Analysis
}

\author{
Wei Xin ${ }^{1}$, Lina Zhang ${ }^{2}$, Jiping Gao ${ }^{1 *}$, Wenzhong Zhang ${ }^{1 *} \mathbb{B}$, Jun $\mathrm{Yi}^{1}$, Xiaoxi Zhen ${ }^{1}$, Congyuan Bi ${ }^{1}$, Dawei He ${ }^{1}$, \\ Shiming Liu' ${ }^{1}$ and Xinyu Zhao ${ }^{1}$
}

\begin{abstract}
Background: Nitrogen-based nutrients are the main factors affecting rice growth and development. Root systems play an important role in helping plants to obtain nutrients from the soil. Root morphology and physiology are often closely related to above-ground plant organs performance. Therefore, it is important to understand the regulatory effects of nitrogen $(\mathrm{N})$ on rice root growth to improve nitrogen use efficiency.
\end{abstract}

Results: In this study, changes in the rice root traits under low N (13.33 ppm), normal N (40 ppm) and high N (120 $\mathrm{ppm}$ ) conditions were performed through root morphology analysis. These results show that, compared with normal $\mathrm{N}$ conditions, root growth is promoted under low $\mathrm{N}$ conditions, and inhibited under high $\mathrm{N}$ conditions. To understand the molecular mechanism underlying the rice root response to low and high $\mathrm{N}$ conditions, comparative proteomics analysis was performed using a tandem mass tag (TMT)-based approach, and differentially abundant proteins (DAPs) were further characterized. Compared with normal N conditions, a total of 291 and 211 DAPs were identified under low and high $\mathrm{N}$ conditions, respectively. The abundance of proteins involved in cell differentiation, cell wall modification, phenylpropanoid biosynthesis, and protein synthesis was differentially altered, which was an important reason for changes in root morphology. Furthermore, although both low and high $\mathrm{N}$ can cause nitrogen stress, rice roots revealed obvious differences in adaptation to low and high $\mathrm{N}$.

Conclusions: These results provide insights into global changes in the response of rice roots to nitrogen availability and may facilitate the development of rice cultivars with high nitrogen use efficiency through root-based genetic improvements.

Keywords: Nitrogen, Proteomics, Root system morphology, Rice

\section{Background}

Rice is one of the most important food crops worldwide, and sustainable development of rice agriculture is an essential part to ensure global food security (Hua et al. 2015). With the acceleration of urbanization, the area of arable land is shrinking, and food production security must be

\footnotetext{
* Correspondence: jipinggao@syau.edu.cn; zwzhong1@syau.edu.cn

'Key Laboratory of Northern Japonica Rice Genetics and Breeding, Ministry of Education and Liaoning Province, Key Laboratory of Northeast Rice Biology and Genetics and Breeding, Ministry of Agriculture, Rice Research Institute of Shenyang Agricultural University, Shenyang 110866, China

Full list of author information is available at the end of the article
}

achieved by increasing yields (Sun et al. 2014). In recent years, researchers have steadily increased rice yield through measures such as improving rice varieties, developing advanced cultivation techniques, and increasing production inputs. Among them, increasing the nitrogen input is one of the most effective measures to increase rice production (Godfray et al. 2010; Liu et al. 2013). However, given the significant increase in rice production, excessive and inappropriate nitrogen fertilizer input has also led to a series of problems, such as a decrease in the nitrogen fertilizer utilization rate and an increase in production cost, air 
pollution, and water pollution cost (Hakeem et al. 2011; Gutiérrez 2012).

Roots not only constitute important organs of rice that absorbs nutrients and moisture but are also the site for assimilation, transformation and synthesis of several substances, such as phytohormones, organic acids, etc. (Wu and Cheng 2014; Meng et al. 2019). Therefore, the morphology and physiology of rice roots are closely related to nitrogen uptake and utilization (Zhang et al. 2009; Lynch 2013). Ju et al. (2015) suggested that Nefficient rice varieties have larger root biomass, deeper root distribution, longer root length, and greater root length density. At the same time, changes in nitrogen availability affect root morphology and physiology (Xu et al. 2012). The morphological and physiological responses of rice roots to changes in $\mathrm{N}$ availability have been studied intensively (Marschner 1995; Mi et al. 2010; Ju et al. 2015). Mild nitrogen deficiency can promote root growth, which is conducive to deep root penetration; appropriate nitrogen supply can increase root number, biomass and density; but excessive nitrogen supply can inhibit root growth (Walch-Liu 2006; Francisco et al. 2015). Ju et al. (2015) showed that within a certain range, root biomass and root oxidation activity increased with increasing nitrogen levels. However, the molecular regulatory mechanisms underlying the morphological and physiological acclimation to different nitrogen levels remain largely unknown. Understanding these mechanisms is of great importance for not only the scientific community involved in research on rice biology but also practical rice breeders, as knowledge of rice root responses to nitrogen availability enables the breeding of rice with high nitrogen use efficiency.

In recent years, the development and application of high-resolution mass spectrometry (MS) and information processing technologies have advanced. Comparative proteomic analysis plays an important role in understanding the mechanisms by which plants adapt to biotic and abiotic stress (Turek et al. 2015; Wang et al. 2016; Hao et al. 2017; Tian et al. 2018a; Tian et al. 2018b). However, to the best of our knowledge, almost no research has been conducted on the response of rice roots to nitrogen nutrition through integrated morphological and proteomic analysis.

In this study, rice plants were subjected to low, control and high $\mathrm{N}$ treatments. The changes in root traits and root proteome profiles were analyzed after 30 days. We found that compared with normal $\mathrm{N}$ conditions, root biomass and the total root length increased under low $\mathrm{N}$ conditions and decreased under high $\mathrm{N}$ conditions. Differences in protein abundance involved in cell division and expansion, lignin synthesis, and nascent protein synthesis could be important factors leading to root morphological changes. The objective of this research is to provide the fundamental information needed to identify strategies employed by rice roots to cope with low and high $\mathrm{N}$ stress. This information could be used for research focused on improving nitrogen use efficiency and production of rice.

\section{Results \\ Architectural Responses of Rice Roots to Nitrogen Availability}

To understand the response mechanism of rice roots to low and high nitrogen, the current study conducted an integrated morphological and proteomic analysis. As shown in Table 1, root biomass (Xin et al. 2019b) and total root length significantly decreased under high $\mathrm{N}$ conditions as compared to normal $\mathrm{N}$ conditions (Table 1, Fig. 1), and increased under low $\mathrm{N}$ conditions. The maximum root length significantly increased under low $\mathrm{N}$ conditions, but no significant effect was observed under high $\mathrm{N}$ conditions. The root diameter was not affected under low $\mathrm{N}$ conditions, but it significantly decreased under high $\mathrm{N}$ conditions. Low $\mathrm{N}$ led to a considerable reduction in root number, but no change under high $\mathrm{N}$. As we previously reported, the nitrogen content increased with increasing nitrogen supply levels (Xin et al. 2019b).

To determine whether the cell division and elongation were affected under different $\mathrm{N}$ treatments, the number and size of cells in root tips were examined. As shown in Fig. 2, compared to normal $\mathrm{N}$ conditions, the length/ width of cell in the elongation zone revealed increased/ no significant change under low $\mathrm{N}$ condition, while the length/width of cell in the elongation zone revealed decreased/decreased under high $\mathrm{N}$ condition. Compared to normal $\mathrm{N}$ conditions, the length/width cell in the maturation zone revealed increased/increased under low $\mathrm{N}$ condition, while the length/width of cell in the maturation zone revealed decreased/no significant change under high $\mathrm{N}$ condition. Compared to normal $\mathrm{N}$ conditions, cell number in the meristematic zone increased under low $\mathrm{N}$ conditions, but did not change significantly under high $\mathrm{N}$ conditions. This result indicates that changes in cell division and cell expansion may contribute to the changed root length of rice under low and high $\mathrm{N}$ conditions.

\section{Overview of Root Proteome Profiles in Response to Different N Treatments}

To understand the molecular basis of changes in rice root morphology and function under different $\mathrm{N}$ regimes, rice root samples under the three $\mathrm{N}$ conditions (low $\mathrm{N}$, normal $\mathrm{N}$, and high $\mathrm{N}$ ) were characterized with tandem mass tag (TMT)-based proteomics. A total of 6169 rice root proteins were identified under the three $\mathrm{N}$ conditions (Fig. S1). Compared to normal N, there were 291 differentially abundant proteins (DAPs) in the 
Table 1 Effects of nitrogen availability on root morphology and nitrogen content

\begin{tabular}{|c|c|c|c|c|}
\hline Treatment & Low $\mathrm{N}$ & Normal N & High N & $P$ value \\
\hline Root biomass (g) & $1.07 \pm 0.08 a$ & $0.84 \pm 0.03 b$ & $0.66 \pm 0.03 c$ & $* * *$ \\
\hline Total root length $(\mathrm{cm})$ & $8032.50 \pm 396.01 a$ & $6694.83 \pm 150.31 b$ & $5423.52 \pm 300.58 c$ & $* * *$ \\
\hline Maximum root length $(\mathrm{cm})$ & $31.30 \pm 0.40 a$ & $27.96 \pm 0.62 b$ & $27.41 \pm 1.08 b$ & $* *$ \\
\hline Root diameter (mm) & $0.46 \pm 0.02 a$ & $0.45 \pm 0.03 a$ & $0.36 \pm 0.04 b$ & $*$ \\
\hline Root number & $181.67 \pm 4.93 b$ & $259.33 \pm 7.77 a$ & $245.00 \pm 8.72 a$ & $* * *$ \\
\hline Root nitrogen content & $2.05 \pm 0.08 c$ & $2.44 \pm 0.11 b$ & $3.39 \pm 0.13 a$ & $* * *$ \\
\hline
\end{tabular}

Values labeled with different letters in the same row indicate significant differences between the nitrogen treatments. As evaluated with ANOVA with Fisher's LSD, ${ }^{*} p<0.05 ;{ }^{* *} p<0.01 ;{ }^{* * *} p<0.001, n=3$. The root biomass and root nitrogen content data have been reported in our previous study (Xin et al. 2019b)

roots under low $\mathrm{N}$ conditions, 173 of which exhibited increased abundance, while 118 exhibited decreased abundance. Compared to normal N, there were 211 DAPs in the roots under high $\mathrm{N}$ conditions, 112 of which exhibited increased abundance, while 99 exhibited decreased abundance. More proteins increased in abundance than decreased in abundance under both low and high $\mathrm{N}$ conditions (Fig. 3a). Among them, 35 proteins were identified as DAPs under both low and high $\mathrm{N}$ conditions, from which, nine DAPs were selected for qRT-PCR

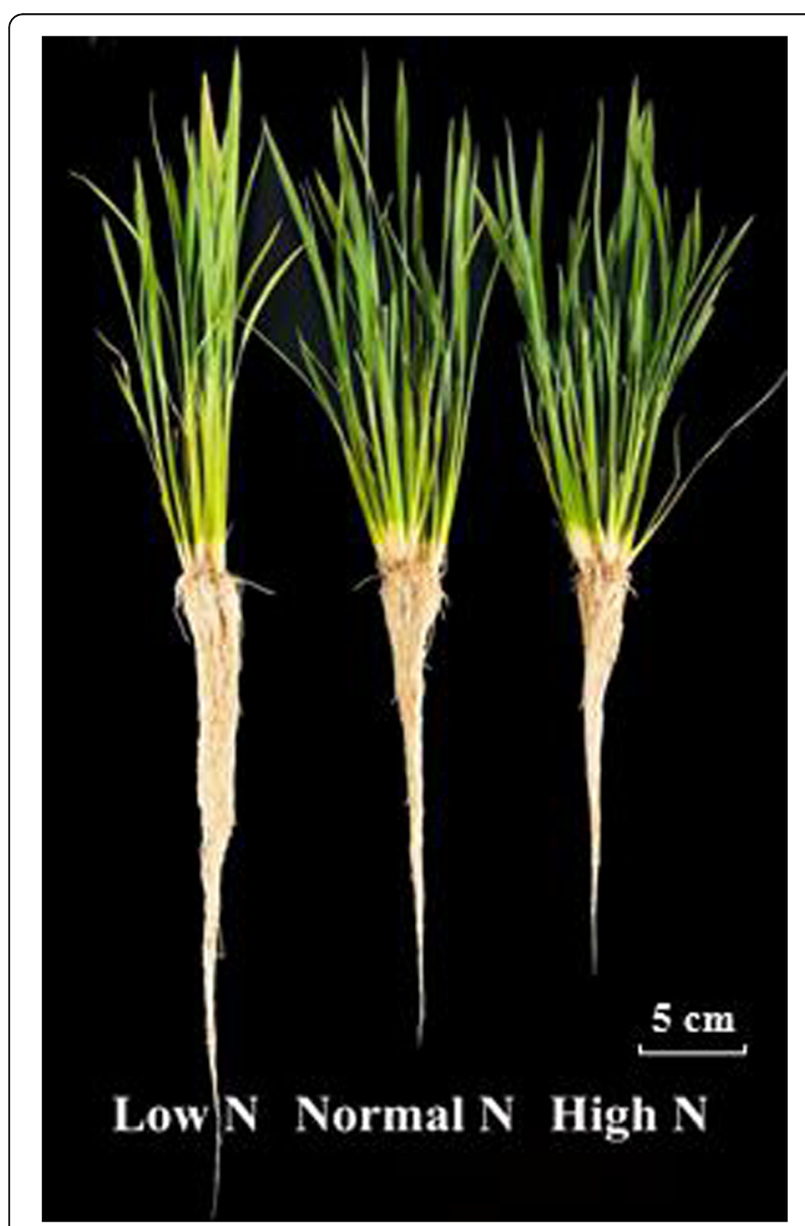

Fig. 1 Effects of $\mathrm{N}$ treatments on roots morphology analysis. The proteome profiles were reliable as a high correlation (0.74) was detected between the qRT-PCR and TMT quantification. (Fig. 3b).

To obtain insights into the main biological functions of DAPs and the metabolic processes involved, Kyoto Encyclopedia of Genes and Genomes (KEGG) analyses were performed. All DAPs enrichment analyses showed that carbon metabolism, nitrogen metabolism, amino acid metabolism, stress and defense-related metabolism, and protein synthesis processes were significantly enriched (Fig. 4a). In addition, enrichment analysis of the DAPs in low and high $\mathrm{N}$ suggested that the top three enriched pathways were caffeine metabolism, phenylalanine metabolism, and purine metabolism (allantoin metabolism) (Fig. 4b).

\section{Nitrogen Uptake and Assimilation in Rice Roots}

As shown in Fig. 5, compared with normal N conditions, the nitrogen transporter proteins NRT2.3, NPF2.11 and AMT1.3 exhibited increased abundance under low $\mathrm{N}$ conditions, while AMT1.3 exhibited decreased abundance under high $\mathrm{N}$ conditions. Five nitrogen assimilation-related proteins were identified as DAPs; all except GLN1.1 exhibited decreased abundance under low $\mathrm{N}$ conditions. GDH2 exhibited increased abundance under high $\mathrm{N}$ conditions. Nineteen amino acid metabolism-related proteins were identified as DAPs, 15 were identified under low nitrogen conditions, all except OMT2, AOC2, AGT2 and GDCSP exhibited decreased abundance. Eight were identified under high $\mathrm{N}$ conditions, all except P5CS and AOC2 exhibited increased abundance. Notably, allantoin metabolism-related proteins exhibited opposite changes in protein relative abundance under low and high $\mathrm{N}$ conditions.

\section{Cell Structure and Growth-Related Proteins}

As shown in Fig. 6, compared with normal $\mathrm{N}$ conditions, 33 cell structure- and growth-related proteins were identified as DAPs. Among the cell structure-associated proteins, eight were identified as DAPs under low $\mathrm{N}$ conditions, and all except TUBA1 exhibited increased abundance. Additionally, six were identified as DAPs under high $\mathrm{N}$ conditions, which exhibited decreased 

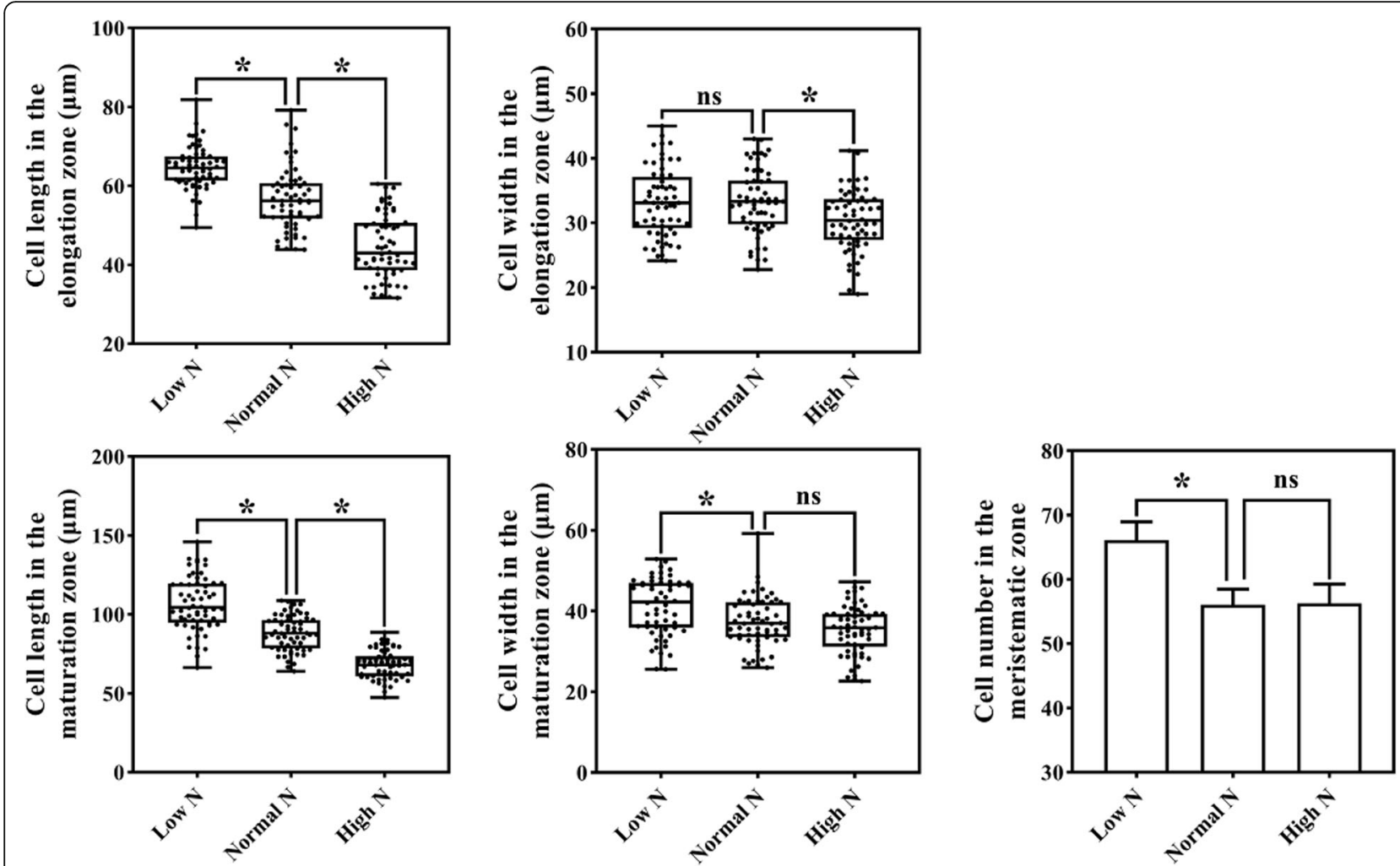

Fig. 2 Changes of cell size in rice roots in response to low and high $\mathrm{N}$. a cell length in the elongation zone. $\mathbf{b}$ cell width in the elongation zone. c cell length in the maturation zone. $\mathbf{d}$ cell width in the maturation zone. e cell number in the meristematic zone, 10,000 $\mu^{2}{ }^{2}$. Asterisks indicate significant differences between the two $\mathrm{N}$ treatments, (as evaluated with ANOVA with Fisher's LSD, ${ }^{*}, p<0.05$, ns, not significant. $n=60$ (cell length and width), $n=9$ (cell number))
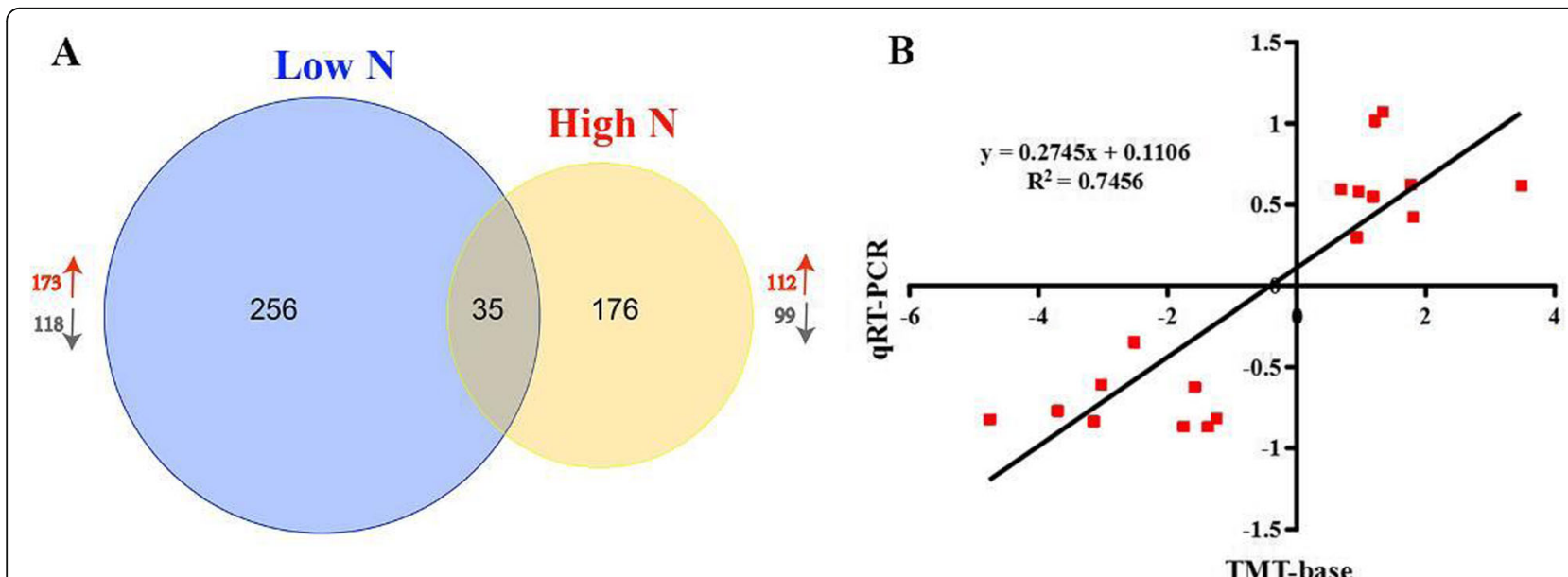

Fig. 3 Proteomic analysis of rice roots under low and high $N$ conditions. a the total number of DAPs under low and high N conditions; $\mathbf{b}$ a qRTPCR assay was carried out for 9 randomly selected DAPs. The values are the $\log _{2}$ (Fold charge) (low $\mathrm{N} /$ control $\mathrm{N}$ or high $\mathrm{N} /$ control $\mathrm{N}$ ) for genes or proteins. The correlation coefficient $\left(R^{2}\right)$ is indicated in the figure 

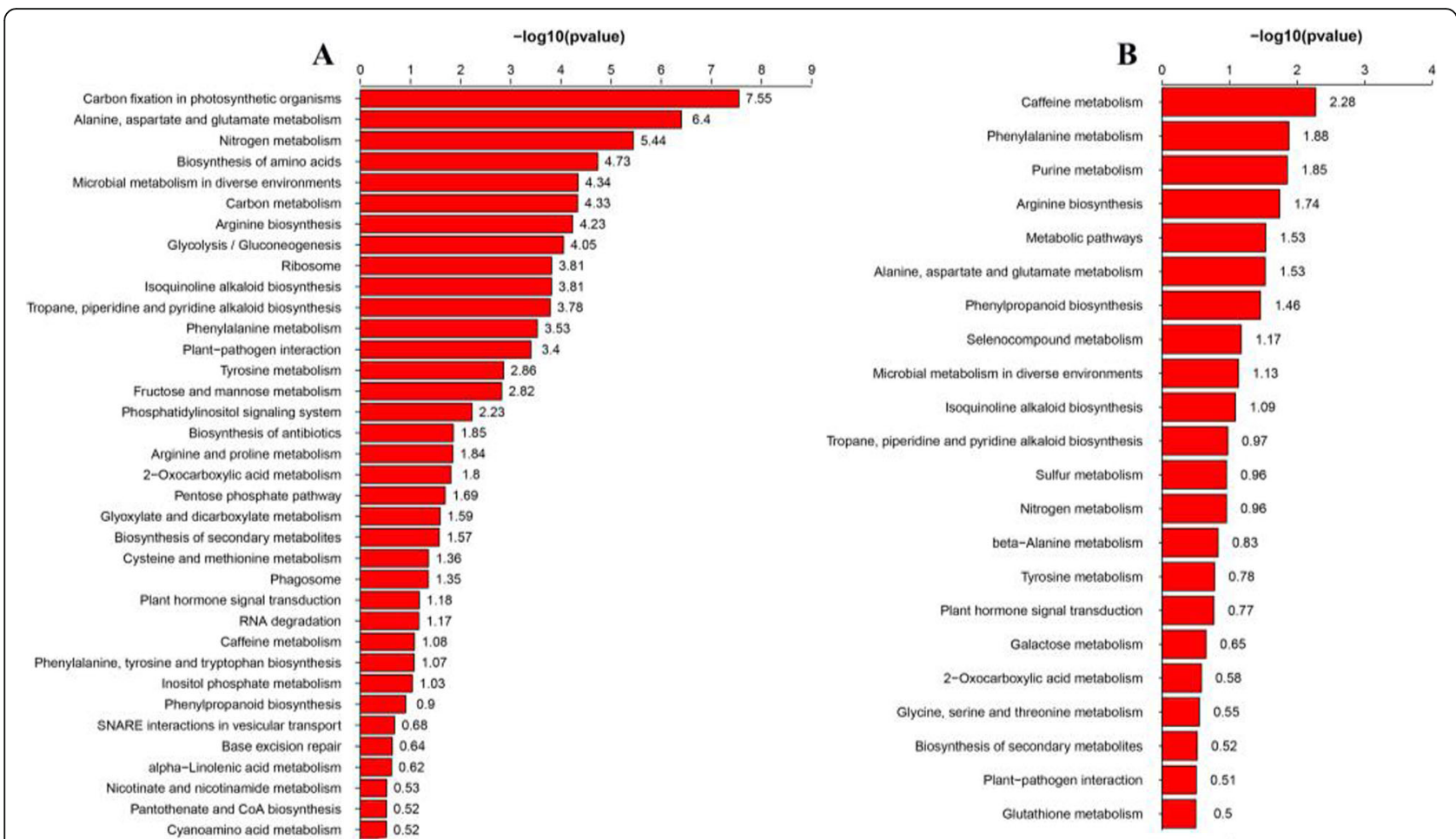

Fig. 4 KEGG analysis of DAPs in rice roots under low and high N conditions. a, KEGG analysis of all identified DAPs under low and high $N$ conditions; b, KEGG analysis of DAPs shared by the low and high $N$ conditions. The -log 10 values of Fisher's exact test $p$ values for the significant pathways are shown on the $X$ axis

\begin{tabular}{|c|c|c|c|c|c|c|c|c|c|c|c|}
\hline \multicolumn{4}{|c|}{ Nitrogen transport } & \multicolumn{4}{|c|}{ Amino acid metabolism } & \multicolumn{3}{|c|}{ Amino acid metabolism } & $\begin{array}{l}1 \\
05\end{array}$ \\
\hline & & & NRT2.3 & & & & ASP2 & & & NAAT-A & \\
\hline & & & NPF2.11 & & & & ARD2 & & & AGT2 & 0 \\
\hline & & & AMT1.3 & & & & CGS1 & & & GPT & -0.5 \\
\hline \multicolumn{4}{|c|}{ Nitrogen assimilation } & & & & P5CS & & & ALAAT & \\
\hline & & & GLN1.1 & & & & BCDH BETA1 & & & FIS1 & -1 \\
\hline & & & GLN1.2 & & & & DHAD & & & LHPI & \\
\hline & & & GDH2 & & & & OMT2 & & & GDCSP & \\
\hline & & & GLT1 & & & & $\mathrm{DAO} 2$ & \multicolumn{4}{|c|}{ Allantoin metabolism } \\
\hline & & & ASN & & & & ASB1 & & & UOX & \\
\hline \multicolumn{4}{|c|}{ Amino acid metabolism } & & & & PDX11 & & & TTL & \\
\hline & & & GOT & & & & GEK1 & & & ALN & \\
\hline & & & GOT2 & & & & DAPC & & & $\mathrm{AAH}$ & \\
\hline $\begin{array}{l}5 \\
\vdots \\
z\end{array}$ & 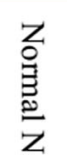 & 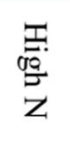 & & $\begin{array}{l}5 \\
\vdots \\
z\end{array}$ & 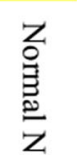 & 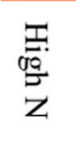 & & $\begin{array}{l}5 \\
\sum\end{array}$ & 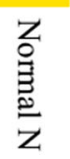 & 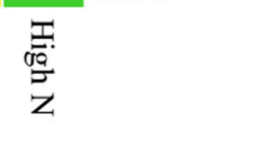 & \\
\hline \multicolumn{12}{|c|}{$\begin{array}{l}\text { Fig. } 5 \text { Differential changes in nitrogen metabolism-related proteins in rice roots under low and high N conditions. Proteins were displayed by } \\
\text { different colors. Relative levels of abundance are showed by a color gradient from low (green) to high (red). For each heatmap from left to right: } \\
\text { Low N, Normal N, High N }\end{array}$} \\
\hline
\end{tabular}




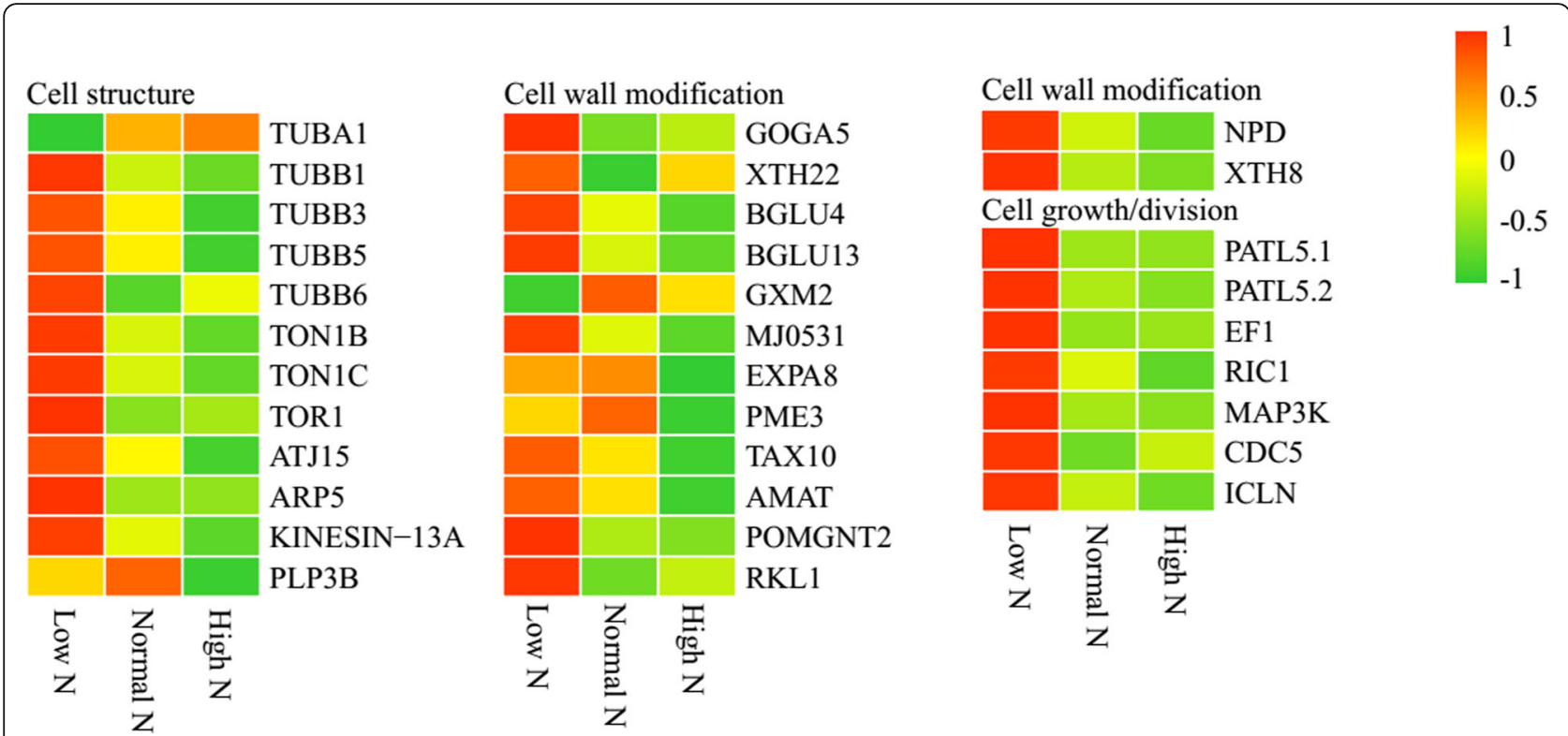

Fig. 6 Differential changes in cell structure- and growth-related proteins in rice roots under low and high N conditions. Proteins were displayed by different colors. Relative levels of abundance are showed by a color gradient from low (green) to high (red). For each heatmap from left to right: Low N, Normal N, High N

abundance. Among the cell wall-related proteins, 11 were identified as DAPs under low $\mathrm{N}$ conditions, and all except GXM2 exhibited increased abundance, six were identified as DAPs under high $\mathrm{N}$ conditions, which exhibited decreased abundance. Among the cell growth/division-related proteins, seven were identified as DAPs under low N conditions, which exhibited increased abundance.

\section{Protein Homeostasis-Related Proteins}

As shown in Fig. 7, compared with normal $\mathrm{N}$ conditions, 62 protein homeostasis-related proteins were identified as DAPs. Among the protein synthesis-related proteins, six were identified under low $\mathrm{N}$ conditions, which exhibited increased abundance, 25 were identified as DAPs under high N conditions, all except RPS28 showed decreased abundance. Among the protein degradationrelated proteins, 18 were identified as DAPs under low $\mathrm{N}$ conditions, all except ERVB, SBT3.5, SPN1, SCPL50.1, SEN102, EDA2, and NEP1 exhibited increased abundance. Additionally, six were identified as DAPs under high $\mathrm{N}$ conditions, all except AMP1 and OCP exhibited increased abundance. Among the protein translationrelated proteins, 4 were identified as DAPs under low $\mathrm{N}$ conditions, which exhibited increased abundance, and seven were identified as DAPs under high N conditions, all except TBCLD15, SYP132 and VPS2.1 exhibited increased abundance.

\section{Stress- and Defense-Related Proteins}

As shown in Fig. 8, compared with normal $\mathrm{N}$ conditions, 39 stress- and defense-related proteins were identified as
DAPs. Seven peroxidases were identified, four were identified under low $\mathrm{N}$ conditions, and all except PRX74 exhibited decreased abundance. In addition, four were identified under high $\mathrm{N}$ conditions, which exhibited increased abundance. Seven glutathione metabolismrelated proteins were identified as DAPs, five were identified as DAPs under low $\mathrm{N}$ conditions, all except GSTU44 and GSTU50 exhibited increased abundance, three were identified as DAPs under high $\mathrm{N}$ conditions, and exhibited increased abundance. Three ascorbaterelated proteins were identified as DAPs, the abundance of AAO3 and APX2 increased under low N conditions, and the abundance of APX1 increased under high $\mathrm{N}$ conditions. Four cytochrome oxidase-related proteins were identified as DAPs, the abundance of CPR and CYP93A2 increased under low $\mathrm{N}$ conditions, while the abundance of COX5B-2 increased and CYP84A1 decreased under high $\mathrm{N}$ conditions. The abundance of the catalase isozyme CATB increased under high $\mathrm{N}$ conditions. Eleven redox-related proteins were identified as DAPs, nine were identified under low $\mathrm{N}$ conditions, all except TR1, DMAS1, FAD and TRXH exhibited increased abundance. Four were identified as DAPs under high $\mathrm{N}$ conditions, all expect QOR and AOX1A exhibited increased abundance. Notably, five calmodulinrelated proteins exhibited increased abundance under high $\mathrm{N}$ conditions.

\section{Phenylpropanoid Biosynthesis}

Phenylalanine metabolism and phenylpropanoid biosynthesis were enriched in both DAPs and shared DAPs 


\begin{tabular}{|c|c|c|c|c|c|c|c|c|c|c|c|c|}
\hline \multicolumn{3}{|c|}{ Protein synthesis } & & \multicolumn{3}{|c|}{ Protein synthesis } & & \multicolumn{4}{|c|}{ Protein degradation } & \multirow{3}{*}{0.5} \\
\hline & & & RPP2A & & & & RPS11.3 & & & & SCPL50.1 & \\
\hline & & & VPE2 & & & & PRS13.2 & & & & CXP2.2 & \\
\hline & & & PSMC6 & & & & RPL7a & & & & CXP2.3 & \multirow{2}{*}{-0.5} \\
\hline & & & RPP2B & & & & RPL7b & & & & SCPL51 & \\
\hline & & & $\mathrm{EIF}-4 \mathrm{G}$ & & & & RPS28 & & & & SCP41 & -1 \\
\hline & & & NUP98A & & & & RPS16a & & & & SEN102 & \\
\hline & & & RPL37a & & & & $\mathrm{SC} 34$ & & & & EDA2 & \\
\hline & & & RPS24B & & & & RPS9d & & & & NEP1 & \\
\hline & & & RPL27C & & & & RPS9b & & & & SCPL50.2 & \\
\hline & & & RPL6 & & & & RPS16b & & & & ASPG1.1 & \\
\hline & & & RPL35AC & \multicolumn{4}{|c|}{ Protein degradation } & & & & ASPG1.2 & \\
\hline & & & RPS9c & & & & ERVB & \multicolumn{4}{|c|}{ Protein translation } & \\
\hline & & & RPL15 & & & & AMP1 & & & & YKT61 & \\
\hline & & & RPL4a & & & & SBT3.5 & & & & AGD12.1 & \\
\hline & & & RPS2D & & & & SBT1.7 & & & & TBCLD15 & \\
\hline & & & RPS11.1 & & & & RPN10 & & & & HSP60.2 & \\
\hline & & & RPL15.1 & & & & SPN1 & & & & AGD12.2 & \\
\hline & & & RPL35AB & & & & $\mathrm{CCP} 1$ & & & & ELC & \\
\hline & & & RPL37b & & & & PUX4 & & & & SYP132 & \\
\hline & & & RPL4b & & & & OCP & & & & GRPE & \\
\hline & & & RPS11.2 & & & & $\mathrm{XCP} 2$ & & & & VPS2.1 & \\
\hline $\begin{array}{l}5 \\
0 \\
\vdots \\
Z\end{array}$ & 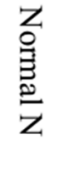 & 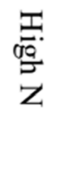 & & $\begin{array}{l}5 \\
0 \\
z \\
z\end{array}$ & 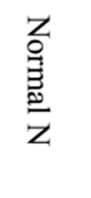 & $\begin{array}{l}\stackrel{\Xi}{g} \\
\stackrel{00}{\sigma} \\
\mathrm{Z}\end{array}$ & & \multicolumn{3}{|c|}{ 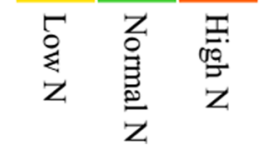 } & TIM9 & \\
\hline $\begin{array}{l}\text { Fig. } 7 \\
\text { differen } \\
\text { Low N, }\end{array}$ & $\begin{array}{l}\text { colors } \\
\text { Norma }\end{array}$ & $\begin{array}{l}\text { tial chat } \\
\text { Relativ } \\
\text { N, Hig }\end{array}$ & $\begin{array}{l}\text { nges in proteir } \\
\text { re levels of abu } \\
\text { h N }\end{array}$ & $\begin{array}{l}\text { stasis-re } \\
\text { are sho }\end{array}$ & $\begin{array}{l}\text { lated p } \\
\text { ved by }\end{array}$ & $\begin{array}{l}\text { oteins i } \\
\text { a color }\end{array}$ & $\begin{array}{l}\text { in rice roots } \\
\text { r gradient fr }\end{array}$ & $\begin{array}{l}\text { and hig } \\
\text { een) to } r\end{array}$ & $\begin{array}{l}\text { h N co } \\
\text { igh (re }\end{array}$ & $\begin{array}{l}\text { nditions. } \\
\text { d). For e }\end{array}$ & $\begin{array}{l}\text { Proteins we } \\
\text { each heatmap }\end{array}$ & right: \\
\hline
\end{tabular}

(Fig. 4). As shown in Fig. 9, the abundance of the main enzymes PAL, 4CL3, CCR1 and CYP93A2 involved in phenylpropanoid biosynthesis increased under low $\mathrm{N}$ conditions. The abundance of the main enzymes ZB8, PAL, CCR1 and CYP84A1 involved in phenylpropanoid biosynthesis decreased under high $\mathrm{N}$ conditions. Root lignin content decreased under low $\mathrm{N}$ conditions, no significant effect was observed under high $\mathrm{N}$ conditions. However, root lignin accumulation amount decreased with increasing nitrogen supply levels (Fig. 10). A total of 7 peroxidases involved in phenylpropanoid biosynthesis were identified as DAPs under low and high $\mathrm{N}$ conditions.

\section{Discussion}

The Distinct and Common Adaptation of Rice Roots to Low Nitrogen and High Nitrogen

Nitrogen nutrients are the main factors affecting rice growth and development. Most previous studies focused on the effects of nitrogen deficiency (Cai et al. 2012; Yang et al. 2015; Curci et al. 2017; Subodh et al. 2018; Qin et al. 2019), while studies on the effects of $\mathrm{N}$ excess have been inadequate. However, the current study has shown that there were obvious differences in the morphological characteristics of rice roots under $\mathrm{N}$ deficiency and excess conditions, especially, root length was increased under low $\mathrm{N}$ conditions, while high $\mathrm{N}$ showed the opposite. Previous studies have shown that, when nutrients are insufficient in the environment, plants can improve nutrient acquisition by promoting root distribution in the medium, thereby maintaining survival (Saengwilai et al. 2014; Wang et al. 2019). This result indicated that root morphological characteristics are of great significance to adapt rice to nitrogen stress.

Nitrogen absorption and assimilation are interdependent in plants, and roots play a key role in this process. Inorganic nitrogen is absorbed and transported by specific transport proteins, such as ammonium transporters (AMTs) and nitrate transporters (NRTs) (Hua et al. 2015). In the present study, compared with normal $\mathrm{N}$ conditions, abundance of AMT1.3, NRT2.3, and NPF2.11 increased under low $\mathrm{N}$ conditions, while abundance of AMT1.3 decreased under high $\mathrm{N}$ conditions. 


\begin{tabular}{|c|c|c|c|c|c|c|c|c|c|c|c|c|}
\hline \multicolumn{3}{|c|}{ Peroxidase } & \multirow[b]{2}{*}{ PER1 } & & \multicolumn{3}{|c|}{ Oxidoreductase } & & \multirow{2}{*}{0.5} \\
\hline & & & & Ascorbate oxidase & & & APX1 & 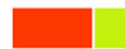 & & & & \\
\hline & & & POD & & & & APX2 & & & & $\begin{array}{l}\text { ISPH } \\
\text { OPR4 }\end{array}$ & \multirow{2}{*}{$\begin{array}{l}0 \\
-0.5\end{array}$} \\
\hline & & & PER12 & & & & AAO3 & & & & \multirow{2}{*}{$\begin{array}{l}\text { QOR } \\
\text { FAD }\end{array}$} & \\
\hline & & & PER72 & \multicolumn{4}{|c|}{ Cytochrome oxidase } & & & & & \\
\hline & & & PRX74 & & & & CYP84A1 & & & & \multirow{2}{*}{$\begin{array}{l}\text { TRXH } \\
\text { ANNAT7 }\end{array}$} & \multirow[t]{4}{*}{-1} \\
\hline & & & PRX 95 & & & & CYP93G1 & & & & & \\
\hline & & & PRX 98 & & & & COX5B-2 & & & & \multirow{2}{*}{$\begin{array}{l}\text { LPR1 } \\
\text { AOX1A }\end{array}$} & \\
\hline \multicolumn{3}{|c|}{ Glutathione } & & & & & $\mathrm{CPR}$ & & & & & \\
\hline & & & GSTU1 & \multicolumn{4}{|c|}{ Catalase isozyme B } & \multicolumn{3}{|c|}{ Calmodulin } & \multirow{6}{*}{$\begin{array}{l}\text { CAM } 1.1 \\
\text { CAM } 1.3 \\
\text { CAM2 } \\
\text { CAM7 } \\
\text { CML16 }\end{array}$} & \\
\hline & & & GSTU 44 & & & & CATB & & & & & \\
\hline & & & GSTU 48 & \multicolumn{3}{|c|}{ Oxidoreductase } & \multirow{3}{*}{$\begin{array}{l}\text { TR1 } \\
\text { WWOX }\end{array}$} & & & & & \\
\hline & & & GSTU 50 & & & & & & & & & \\
\hline & & & GSTZ1 & & & & & & & & & \\
\hline & & & GGT3 & & & & DMAS1 & & & & & \\
\hline $\begin{array}{l}5 \\
\vdots \\
z\end{array}$ & $\begin{array}{l}Z \\
O \\
\stackrel{0}{\Xi} \\
Z \\
Z\end{array}$ & 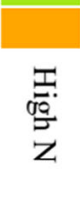 & GRXS1 & $\begin{array}{l}5 \\
\vdots \\
z\end{array}$ & \multicolumn{2}{|c|}{ 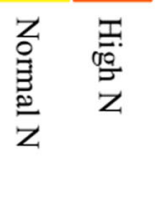 } & & $\sum_{z}^{5}$ & \multicolumn{2}{|c|}{ 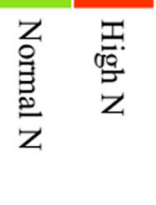 } & (1) & \\
\hline \multicolumn{13}{|c|}{$\begin{array}{l}\text { Fig. } 8 \text { Differential changes in stress- and defense-related proteins in rice roots under low and high N conditions. Proteins were displayed by } \\
\text { different colors. Relative levels of abundance are showed by a color gradient from low (green) to high (red). For each heatmap from left to right: } \\
\text { Low N, Normal N, High N }\end{array}$} \\
\hline
\end{tabular}

Glutamine synthetase (GS) is a key enzyme in nitrogen assimilation (Yang et al. 2016). In rice, the GS protein family has three members, namely, GLN1.1, GLN 1.2, and GLN 1.3, and the function of GLN1.1 cannot be compensated by GLN1.2 and GLN1.3 (Tabuchi et al. 2005). In our study, we observed that compared with normal $\mathrm{N}$ conditions, the abundance of GLN1.1 increased under low N conditions. This result indicated that GLN1.1 may have the ability to promote nitrogen assimilation to compensate for nitrogen deficiency. In this study, compared with normal $\mathrm{N}$ conditions, the abundance of GDH2 increased under high $\mathrm{N}$ conditions, and the high abundance of GDH2 may alleviate ammonium toxicity caused by high $\mathrm{N}$ conditions. Interestingly, we observed different responses of allantoin metabolism to low $\mathrm{N}$ and high $\mathrm{N}$ conditions. The synthesis of allantoin was inhibited and decomposition was promoted by low $\mathrm{N}$, and the opposite was observed under high $\mathrm{N}$ conditions. Lescano et al. (2016) showed that osmotic stress can induce the expression of UOX and AS in the allantoin synthesis pathway and inhibit the expression of ALN in the decomposition pathway, which ultimately leads to an increase in allantoin levels. We suggest that $\mathrm{NH}_{3}{ }^{+}$produced by allantoin decomposition for nitrogen remobilization, may supplement $\mathrm{N}$ deficiency. Moreover, the accumulation of allantoin will be able to mobilize the specific response process to adapt to high $\mathrm{N}$ stress. Many studies have also demonstrated that plant antioxidant systems are rapidly affected by changes in nutrient conditions (Luo et al. 2015; Curci et al. 2017; Bellegarde et al. 2019). In the current study, a large number of stress-related proteins increased in abundance under low $\mathrm{N}$ and high $\mathrm{N}$ conditions. Among them, calmodulin exhibited a strong response to high $\mathrm{N}$. Calmodulin is a calcium receptor that is widely found in eukaryotes and is involved in plant growth and the response to various forms of stress (Lee et al. 2005; Chinpongpanich et al. 2012).

In summary, we suggest that under low $\mathrm{N}$ conditions, the purpose of rice roots morphology and protein level changes is to enhance $\mathrm{N}$ uptake and assimilation to guarantee optimum growth. Under high $\mathrm{N}$ conditions, rice root may be adapted to high $\mathrm{N}$ stress by increasing the abundance of calmodulin and GDH2, as well as the accumulation of allantoin. Similarly, both low and high $\mathrm{N}$ can induce expression of antioxidant-related proteins to adapt to stress.

\section{Potential Regulatory Mechanisms of Root Morphology Response to Low Nitrogen and High Nitrogen}

In the present study, the number and size of cells in root tips were affected by low and high N. Proteomics analysis results also shown that, the abundance of proteins involved in cell development was affected by variations in $\mathrm{N}$ availability, for example, the expression of microtubule-associated proteins was induced by low $\mathrm{N}$ but inhibited by high $\mathrm{N}$. Microtubules are major 


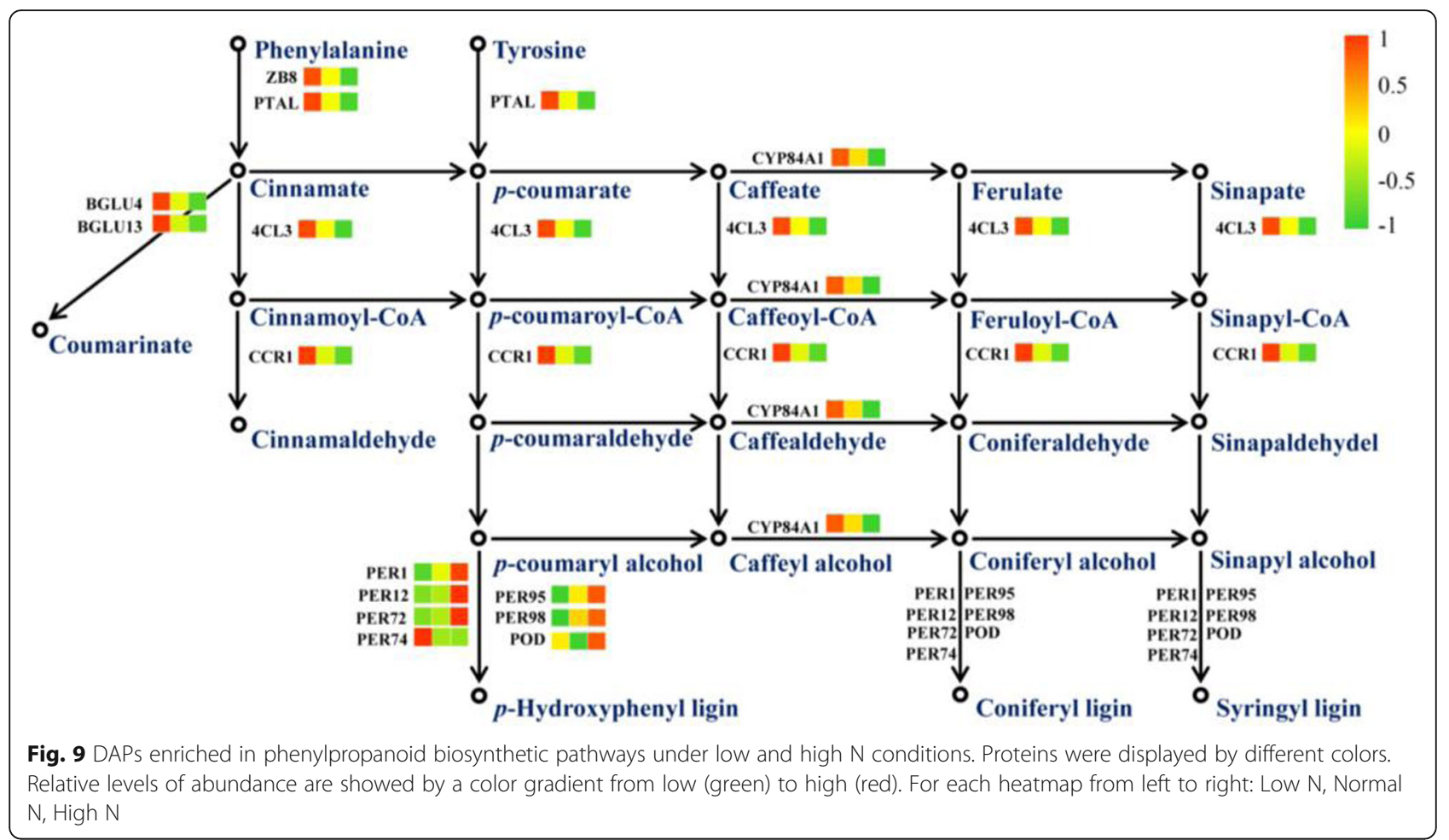

structural components of eukaryotic cells and play a key role in regulating cell division, cell proliferation and cell morphology (Wasteneys and Yang 2004). Qin et al.'s (2019) research on rapeseed roots under nitrogen deficiency also found similar results. Cell elongation not only increases cytoplasm, but also promotes cell wall components (such as cellulose, hemicellulose, pectin, ect.) synthesis to maintain cell wall thickness. In the current study, proteins related to cellulose, hemicellulose, and pectin were identified as DAPs under low and high $\mathrm{N}$ conditions. Furthermore, compared with normal $\mathrm{N}$ conditions, abundance of several cell growth/ division- related proteins increased under low $\mathrm{N}$ conditions. Therefore, the response of rice root morphology to $\mathrm{N}$ availability could be achieved through coordination of these relevant proteins involved in cell structure, cell wall modification and cell division. This coordination could ultimately trigger changes in root morphology
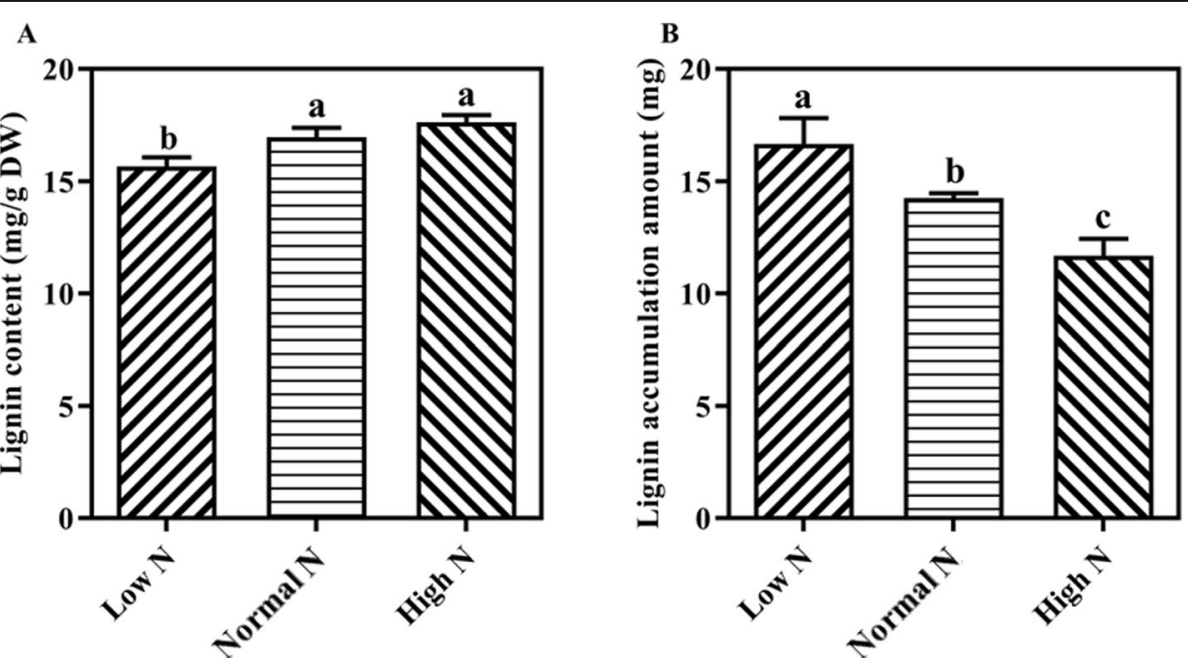

Fig. 10 Rice root lignin content and accumulation amount response to low and high N. Values labeled with different letters in same row indicate significant difference between the $N$ treatments, (as evaluated with ANOVA with Fisher's LSD, $p<0.05, n=3$ ), DW, Dry weight 
with nitrogen availability. Lignin is a major component in the formation of plant skeletons and plays an important role in plant resistance to biotic and abiotic stresses. Phenylalanine/tyrosine ammonia-lyase (PTAL), 4coumarate-CoA ligase (4CL), and cinnamoyl-CoA reductase (CCR) are key enzymes involved in the lignin synthesis pathway. In this study, we observed that the abundance of PTAL, 4CL, and CCR were induced by low $\mathrm{N}$ and inhibited by high $\mathrm{N}$. The differences in the abundance of these proteins were in line with the changed lignin accumulation amount under low $\mathrm{N}$ and high $\mathrm{N}$ conditions. Additionally, this study suggests that the main reason for the low lignin content under low nitrogen conditions is fast root growth. Well known, biomass accumulation is related to protein synthesis. The current study revealed that compared to control $\mathrm{N}$ conditions, protein synthesis was promoted by low $\mathrm{N}$ conditions and inhibited by high $\mathrm{N}$ conditions. Indeed, previous studies have suggested that protein synthesis is one of the main targets for growth control in response to changes in the environment (Wang et al. 2014; Zhou et al. 2017). These results suggest that, differentially abundant proteins involved in cell differentiation, lignin synthesis, and nascent protein synthesis in roots are important factors leading to root morphological changes among the three nitrogen treatments.

\section{Conclusion}

In this study, we compared root morphological and proteomic profiles across three environmental conditions ( $\mathrm{N}$ levels). Research results suggest that nitrogen may affect root growth by regulating biological processes such as cell development, phenylpropanoid biosynthesis and protein synthesis. In addition, we also found that the adaptation mechanism of rice roots differs greatly under low $\mathrm{N}$ and high $\mathrm{N}$ conditions. Under low $\mathrm{N}$ conditions, rice roots enhance nutrient uptake and utilization by increasing $\mathrm{N}$ transport, assimilation and remobilization (glycine, allantoin and protein breakdown) to maintain optimum rice growth and development. Under high $\mathrm{N}$ conditions, rice roots determine the abundance of the antioxidant system, calmodulin, allantoin and glutamate dehydrogenase to improve tolerance to high $\mathrm{N}$ stress. This study elucidated the molecular mechanism underlying the $\mathrm{N}$-mediated determinants of root growth and development, and provides new insights into improving nitrogen use efficiency in rice (Fig. 11).

\section{Materials and Methods}

\section{Plant Materials, Mitrogen Treatment and Analysis of Root} Characteristics

The experiment was carried out at Shenyang Agricultural University Rice Research Institute, Liaoning Province, China $\left(41^{\circ} 49 \mathrm{~N}, 123^{\circ} 34 \mathrm{E}\right)$. Mature rice seeds (cv. 'shengnong265' Japonica China) were obtained from the Shenyang Agricultural University Rice Research Institute. Seeds were surface-sterilized with $0.01 \% \mathrm{HgCl}_{2}$, allowed to germinate at $28^{\circ} \mathrm{C}$ for $2 \mathrm{~d}$, and further cultured in a greenhouse (average temperature of $28 / 25^{\circ} \mathrm{C}$, photoperiod of $10 \mathrm{~h}$ day $/ 14 \mathrm{~h}$ night). At three-leaf stage, the seedlings were subjected to $13.33 \mathrm{ppm}$ (low N), 40 ppm (normal N), or $120 \mathrm{ppm}$ (high $\mathrm{N}$ ) of nitrogen using $\mathrm{NH}_{4} \mathrm{NO}_{3}$ as the $\mathrm{N}$ source and grown in hydroponics for $30 \mathrm{~d}$ during the growing season. The formula for the hydroponic solution was slightly improved as described by Li et al. (2012). All treatments had ten replicates with a completely random design. After $30 \mathrm{~d}$ (Tillering stage), the relevant indicators were determined.

Roots were sampled after $30 \mathrm{~d}$ of treatments, three biological replicates per treatment. Root number, total root length and root diameter were measured with WinRHIZO Pro 2013e software (Regent Instruments Inc., Quebec, Canada). Maximum root length (the length of the longest whole root from root cap to root tip) was measured with a ruler. Then, the roots were dried in an oven at $80^{\circ} \mathrm{C}$ to a constant weight for measuring root biomass. Samples were powdered with a micropulverizer (FZ102, Tianjin, China) to measure root nitrogen content using an elemental analyzer (Elementar Vario MACRO cube, Hanau, Germany). Lignin content was determined with the acetyl bromide method as described previously (Foster et al. 2010). Lignin accumulation amount was calculated by lignin content and root biomass.

After $30 \mathrm{~d}$ of nitrogen treatment, cell size and number were investigated in $1-\mathrm{cm}$ root segments starting from the root tip. The root segments (three individual rice plants for each treatment) were fixed using 70\% FAA fixative. Sectioning and staining were performed using modified method of Qin et al. (2019). Twenty cells were selected from each root segment in the elongation and maturation zone to determine the length and width using CaseViewer (3DHISTECH, Budapest, Hungary). Three fields of each root segment in the meristematic area were selected and measured cell number, record the number of cells in $10,000 \mu \mathrm{m}^{2}$ (Fig. S2).

For experimental variables, one-way of variance (ANOVA) was applied to assess differences among treatments with SPSS 19.0 (Softonic International, Barcelona, Spain) software and drawn using GraphPad Prism 8 (GraphPad, San Diego, USA) software. Significant differences $(p<0.05)$ between treatments are indicated by different letters according to Fisher's LSD. The data presented are the means \pm standard errors.

\section{Protein Extraction, Trypsin Digestion and TMT Labeling}

Thirty days after nitrogen treatment started, root system samples were collected from 9:00 am to 10:00 am. Three biological replicates per treatment (low $\mathrm{N}$, normal $\mathrm{N}$, 


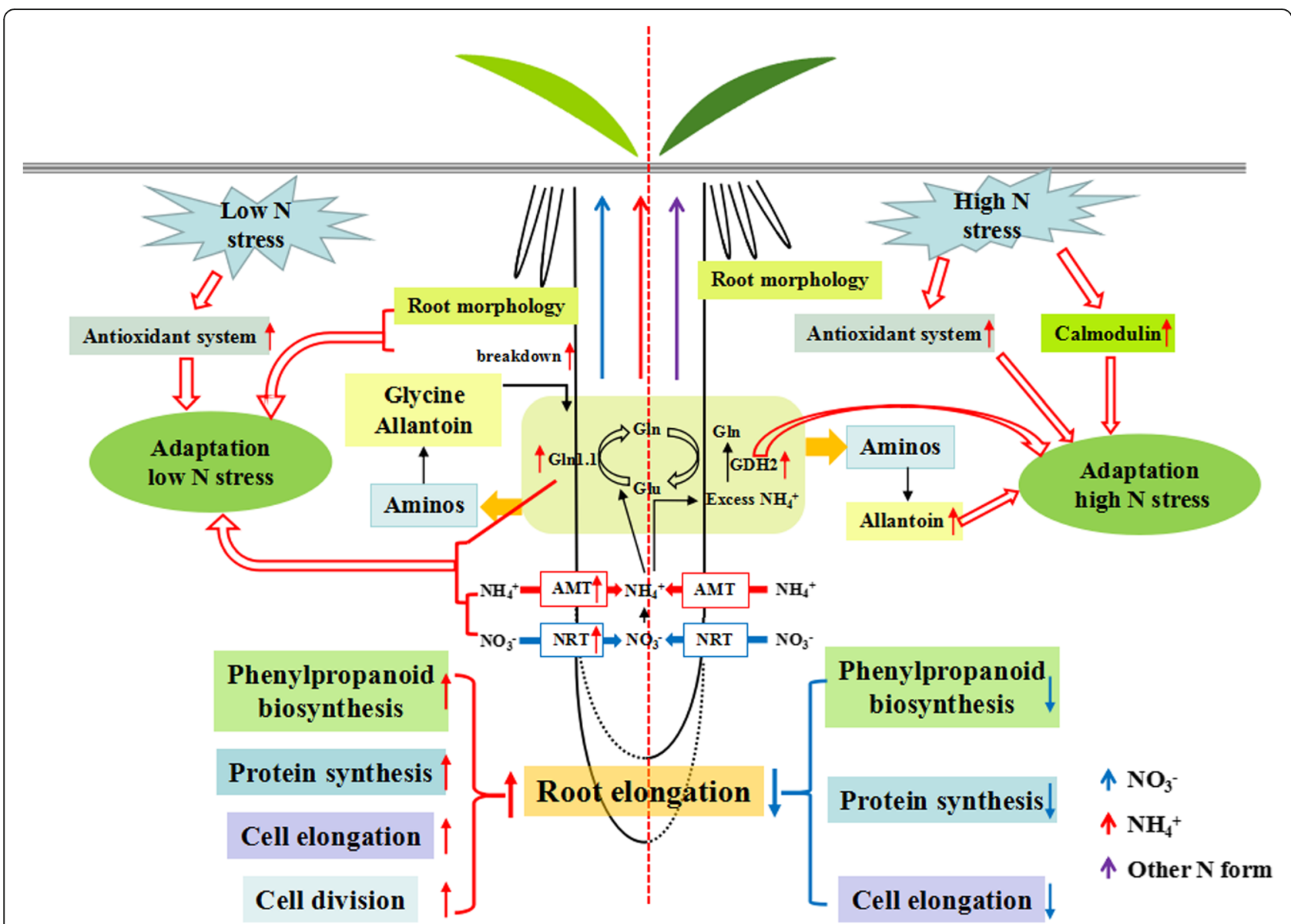

Fig. 11 Schematic model representing the growth and stress in the roots of rice when exposed to low and high $\mathrm{N}$ conditions

and high $\mathrm{N}$ ) were used for subsequent TMT-based proteomic analysis. Total proteins were extracted using the cold acetone method (Zhang et al. 2018). Samples were ground to a powder in liquid nitrogen and then dissolved in $2 \mathrm{~cm}^{3}$ of lysis buffer (8 M urea, 2\% SDS, 1× protease inhibitor cocktail (Roche Ltd., Basel, Switzerland)), followed by sonication on ice for $30 \mathrm{~min}$ and centrifugation at $13000 \mathrm{~g}$ for $30 \mathrm{~min}$ at $4{ }^{\circ} \mathrm{C}$. The supernatant was transferred to a fresh tube. For each sample, proteins were precipitated with ice-cold acetone at $-20^{\circ} \mathrm{C}$ overnight. The precipitates were washed with acetone three times and redissolved in $8 \mathrm{M}$ urea by sonication on ice. Protein quality was examined by SDSPAGE. The BCA Protein Assay Kit was used to determine the protein concentration in the supernatant. For each condition, one hundred micrograms of protein was transferred into a new tube and adjusted to a final volume of $100 \mathrm{~mm}^{3}$ with $8 \mathrm{M}$ urea. Then, $11 \mathrm{~mm}^{3}$ of $1 \mathrm{M}$ DTT (DL-dithiothreitol) was added, and the samples were incubated at $37^{\circ} \mathrm{C}$ for $1 \mathrm{~h}$. Then, the samples were centrifuged at $14000 \mathrm{~g}$ for $10 \mathrm{~min}$ in a $10 \mathrm{~K}$ ultrafiltration tube (Millipore). A total of $120 \mathrm{~mm}^{3}$ of $55 \mathrm{mM}$ iodoacetamide was added to the sample, and the mixture was incubated for $20 \mathrm{~min}$ protected from light at room temperature. The precipitates were washed by $1 \mathrm{~cm}^{3}$ pre-chilled 90\% acetone aqueous solution for twice and then re-dissolved in $100 \mathrm{~mm}^{3} 100 \mathrm{mM}$ TEAB. The proteins were then digested with sequence-grade modified trypsin (Promega, Madison, WI) at $37^{\circ} \mathrm{C}$ overnight. Then, the digested samples were centrifuged at $13500 \mathrm{~g}$ for $12 \mathrm{~min}$, dried under vacuum, and dissolved in 500 $\mathrm{mM}$ TEAB. The resultant peptide mixture was labeled with TMT- 10Plex Isobaric Mass Tag Labeling Kit (Thermo Fisher Scientific, MA, USA) for $2 \mathrm{~h}$ at room temperature. The labeled peptide samples were then pooled and lyophilized in a vacuum concentrator.

\section{HPLC Fractionation and LC-MS/MS Analysis}

The peptide mixture was redissolved in buffer A (buffer A: $20 \mathrm{mM}$ ammonium formate in water, $\mathrm{pH} 10.0$, adjusted with ammonium hydroxide) and then fractionated by high-pH separation using an Ultimate 3000 system (Thermo Fisher Scientific, MA, USA) connected to a reversed-phase column (XBridge C18 column, $4.6 \mathrm{~mm} \times$ $250 \mathrm{~mm}, 5 \mu \mathrm{m}$, Waters Corporation, MA, USA). High$\mathrm{pH}$ separation was performed using a linear gradient 
starting from $5 \%$ B to $45 \%$ B over 40 min (buffer B: 20 $\mathrm{mM}$ ammonium formate in $80 \% \mathrm{ACN}, \mathrm{pH} 10.0$, adjusted with ammonium hydroxide). The column was reequilibrated to the initial conditions for $15 \mathrm{~min}$. The column flow rate was maintained at $1 \mathrm{~cm}^{3} / \mathrm{min}$, and the column temperature was maintained at $30^{\circ} \mathrm{C}$. Twelve fractions were collected; each fraction was dried in a vacuum concentrator for the next step.

Peptide fractions were resuspended with $30 \mathrm{~mm}^{3}$ of solvent C (C: water with $0.1 \%$ formic acid; D: ACN with $0.1 \%$ formic acid), separated by nanoLC and analyzed by online electrospray tandem MS. The experiments were performed on an Easy-nLC 1000 system (Thermo Fisher Scientific, MA, USA) connected to an Orbitrap Fusion Tribrid mass spectrometer (Thermo Fisher Scientific, MA, USA) equipped with an online nanoelectrospray ion source. A $10-\mathrm{mm}^{3}$ peptide sample was loaded onto the trap column (Thermo Scientific Acclaim PepMap C18, $100 \mu \mathrm{m} \times 2 \mathrm{~cm}$ ) with a flow of $10 \mathrm{~mm}^{3} / \mathrm{min}$ for 3 min and subsequently separated on an analytical column (Acclaim PepMap C18, $75 \mu \mathrm{m} \times 15 \mathrm{~cm}$ ) with a linear gradient from $2 \% \mathrm{D}$ to $40 \% \mathrm{D}$ in $70 \mathrm{~min}$. The column was re-equilibrated to the initial conditions for $10 \mathrm{~min}$. The column flow rate was maintained at $300 \mu \mathrm{m}^{3} / \mathrm{min}$. An electrospray voltage of $2 \mathrm{kV}$ against the inlet of the mass spectrometer was used. The Fusion mass spectrometer was operated in data-dependent acquisition mode to switch automatically between MS and MS/MS acquisition. Full-scan MS spectra (m/z 350-1550) were acquired with a mass resolution of $120 \mathrm{~K}$, followed by sequential highenergy collisional dissociation (HCD) MS/MS scans with a resolution of $30 \mathrm{~K}$. The intense signals in the MS spectra (>1e4) were subjected to an additional MS/MS analysis. The automatic gain control (AGC) values for MS and MS/MS were set to $4 \mathrm{e} 5$ and $8 \mathrm{e} 4$, respectively. The maximum ion injection times for MS and MS/MS were 50 and $100 \mathrm{~ms}$, respectively. The isolation window was set to 1.6 Da. In all cases, one microscan was recorded using dynamic exclusion of $30 \mathrm{~s}$.

\section{Database Search}

Tandem mass spectra were extracted, charge state deconvoluted and deisotoped by Mascot Distiller version 2.6. Then, the MS data were transformed into MGF files with Proteome Discoverer 1.2 (Thermo, Pittsburgh, PA, USA) and analyzed using the Mascot search engine (Matrix Science, London, UK; version 2.3.2). The Mascot database was set up for protein identification using the rice (Oryza sativa) protein information from IRGSP-1.0 in ensemble (version 38) database with the following parameters: digestion enzyme, trypsin; 1 missed cleavage allowed. Mascot was searched with a fragment ion mass tolerance of $0.050 \mathrm{Da}$ and a parent ion tolerance of 20.0 ppm. Carbamidomethyl on cysteine and TMT-10-plex on lysine and the $\mathrm{N}$-terminus were specified in Mascot as fixed modifications. Deamidation of asparagine and glutamine, and oxidation of methionine and acetyl at the $\mathrm{N}$-terminus were specified in Mascot as variable modifications.

\section{Protein Identification, Quantification and Annotation Analysis}

Protein identification results were accepted if a false discovery rate (FDR) of less than $1.0 \%$ was achieved by the Scaffold Local FDR algorithm. Proteins that contained similar peptides and could not be differentiated based on MS/MS analysis alone were grouped to satisfy the principles of parsimony. Protein quantification was carried out for those proteins identified in all the samples with $\geq 2$ unique spectra. Protein relative quantification was based on the ratios of reporter ions, which reflect the relative abundance of peptides. The Mascot search results were averaged using medians and quantified. Fold changes $>1.2$ and t-test $p<0.05$ were used as a threshold to identify the significantly different proteins. Proteins were annotated against the GO (http://www.geneontology.org) and KEGG (http://kobas.cbi.pku.edu.cn/) databases for identification of function. Significant GO functions and pathways were examined within DAPs with $p$ value $\leq 0.05$. Heatmap analysis was performed using the OmicShare tools, a free online platform for data analysis (http://www.omicshare.com/tools).

\section{Total RNA Extraction and Verification of the Proteomic Profile}

Total RNA extraction was performed with the Eastep Super Total RNA Extraction Kit (Promega), and firststrand cDNA was synthesized with the PrimeScript RT Master Mix (TaKaRa). Real-time RT-PCR was conducted based on the method described by Xin et al. (2019a). The primers used for RT-PCR analysis are listed in Table S3. Calculation of correlation coefficients and plotting of the proteomic profile and RT-PCR data were performed with Origin 9 (Northampton, MA, USA) software.

\section{Supplementary Information}

The online version contains supplementary material available at https://doi. org/10.1186/s12284-020-00443-y.

Additional file 1: Figure S1. Basic protein identification information statistics by TMT analysis.

Additional file 2: Figure S2. Schematic diagram of meristem, elongation and maturity zone of the root tip.

Additional file 3: Table S1. Abbreviations list.

Additional file 4: Table S2. Proteomic experiment design.

Additional file 5: Table S3. Sequences of primers used in this study. 
Additional file 6: Table S4. DAPs information involved in nitrogen metabolism, cell structure and growth, protein homeostasis, and stress related proteins under low and high $\mathrm{N}$ conditions.

Additional file 7: Table S5. Peptide information list for protein identification results.

Additional file 8: Table S6. Protein information list for protein identification results.

\section{Abbreviations}

AAH: Allantoate deiminase; AGD12.1: ADP-ribosylation factor GTPaseactivating protein; AGD12.2: ADP-ribosylation factor GTPase-activating protein; AGT2: Alanine-glyoxylate aminotransferase 2; ALAAT: Alanine aminotransferase 2; ALN: Allantoinase; AMAT: Methanol Oanthraniloyltransferase; AMP1: Glutamate 2; AMT1.3: Ammonium transporter 1 member 3; ANNAT7: Annexin D7; AOX1A: Ubiquinol oxidase; APX1: Lascorbate peroxidase 1; APX2: L-ascorbate peroxidase 2; ARD2: Acireductone dioxygenase 2; ARP5: Actin-related protein 5; ASB1: Anthranilate synthase beta subunit 1; ASN: Asparagine synthetase 1; ASP2: Aspartic proteinase Asp1-like; ASPG1.1: ASPARTIC PROTEASE IN GUARD CELL 1.1; ASPG1.2: ASPA RTIC PROTEASE IN GUARD CELL 1.2; ATJ15: Chaperone protein dnaJ 15; BCDH BETA1: 2-oxoisovalerate dehydrogenase subunit beta 1; BGLU13: Betaglucosidase 13; BGLU4: Beta-glucosidase 4; CAM 1.1: Calmodulin-1.1; CAM 1.3: Calmodulin-1.3; CAM2: Calmodulin-2; CAM7: Calmodulin-7; CATB: Catalase isozyme B; CCP1: Cysteine proteinase 1 precursor; CDC5: Cell division cycle 5; CGS1: Cystathionine gamma-synthase 1; CML16: Calciumbinding protein CML16; COX5B-2: Cytochrome c oxidase subunit 5b-1; CPR: NADPH--cytochrome P450 reductase; CXP2.2: Serine carboxypeptidase II-2; CXP2.3: Serine carboxypeptidase II-3; CYP84A1: Cytochrome P450 84A1; CYP93G1: Cytochrome P450 93G1; DAO2: Amine oxidase; DAPC: Nsuccinyldiaminopimelate aminotransferase; DAPs: Differentially abundant proteins; DHAD: Dihydroxy-acid dehydratase; DMAS1: NAD(P)H-dependent oxidoreductase 1; EDA2: Serine protease; EF1: Elongation factor 1-delta 1; EIF4G: Eukaryotic translation initiation factor 4G; ELC: Protein ELC; ERVB: Ervatamin-B; EXPA8: Expansin-A8; FAD: Inactive tetrahydrocannabinolic acid synthase; FIS1: 1-pyrroline-5-carboxylate dehydrogenase; GDCSP: Glycine dehydrogenase; GDH2: Glutamate dehydrogenase 2; GEK1: D-aminoacyltRNA deacylase; GGT3: Glutathione gamma-glutamylcysteinyltransferase; GLN1.1: Glutamine synthetase cytosolic isozyme 1-1; GLN1.2: Glutamine synthetase cytosolic isozyme 1-2; GLT1: Glutamate synthase 2; GOGA5: Golgin-84; GOT: Aspartate aminotransferase; GOT2: Aspartate aminotransferase 2; GPT: L-alanine:2-oxoglutarate aminotransferase; GRPE: GrpE nucleotide exchange factor domain-containing protein; GRXS1: Monothiol glutaredoxin-S1; GSTU 44: Glutathione S-transferase 44; GSTU 48: Glutathione S-transferase 48; GSTU 50: Glutathione S-transferase 50; GSTU1: Glutathione S-transferase 1; GSTZ1: Glutathione S-transferase 2; GXM2: Glucuronoxylan 4-O-methyltransferase 1; High N: High nitrogen; HSP60.2: Chaperonin CPN60.2; ICLN: Chloride conductance regulatory; ISPH: 4-hydroxy-3-methylbut-2-enyl diphosphate reductase; KINESIN13A: Kinesin-13A; LHPI: Ornithine cyclodeaminase; Low N: Low nitrogen; LPR1: Multicopper oxidase; MAP $3 \mathrm{~K}$ : PI-PLC X domain-containing protein; MJ0531: Universal stress protein MT2085 isoform X2; N: Nitrogen; NAATA: Nicotianamine aminotransferase A; NEP1: Aspartic proteinase nepenthesin1; Normal N: Normal nitrogen; NPD: Endoglucanase; NPF2.11: Protein NRT1/ PTR FAMILY 2.11; NRT2.3: High-affinity nitrate transporter 2.3;

NUP98A: Nuclear pore complex protein; OCP: Oryzain alpha chain precursor; OMT2: O-methyltransferase 2; OPR4: Putative 12-oxophytodienoate reductase 4; P5CS: Delta-1-pyrroline-5-carboxylate synthase; PATL5.1: Patellin-3.1; PATL5.2: Patellin-3.2; PDX11: Pyridoxal 5'-phosphate synthase subunit; PER1: Peroxidase 1; PER12: Peroxidase 12; PER72: Peroxidase 72; PLP3B: Thioredoxin domain-containing; PME3: Pectinesterase; POD: Peroxidase A2; POMGNT2: Protein O-linked-mannose beta-1,4-Nacetylglucosaminyltransferase 2; PRS13.2: 40 S ribosomal protein S13.2; PRX 95: Peroxidase 95; PRX 98: Peroxidase 98; PRX74: Peroxidase 74; PSMC6: 265 protease regulatory subunit $6 \mathrm{~B}$ homolog; PUX4: Plant UBX domaincontaining protein 4; QOR: Oxidoreductase; RIC1: Ras-related protein RIC1; RKL1: Leucine Rich Repeat family protein; RPL15: 60S ribosomal protein L15; RPL15.1: 60S ribosomal protein L15.1; RPL27C: 60S ribosomal protein L27-3; RPL35AB: 605 ribosomal protein L35a-3; RPL35AC: 605 ribosomal protein L35a-1; RPL37a: 60 S ribosomal protein L37a isoform 2; RPL37b: 605 ribosomal protein $L 37 a$; RPL4a: $60 S$ ribosomal protein $L 4 a$; RPL4b: $60 S$ ribosomal protein
L4b; RPL6: 605 ribosomal protein L6-3; RPL7a: 60S ribosomal protein L7a; RPL7b: 60S ribosomal protein L7b; RPN10: 265 proteasome non-ATPase regulatory subunit 4; RPP2A: 605 acidic ribosomal protein P2A; RPP2B: 605 acidic ribosomal protein p2b; RPS11.1: 40S ribosomal protein S11.1; RPS11.2: 40 S ribosomal protein S11.2; RPS11.3: 40 S ribosomal protein S11.3; RPS16a: 40S ribosomal protein S16a; RPS16b: 40S ribosomal protein S16b; RPS24B: 40S ribosomal protein S24-1; RPS28: Os10g0411700, partial; RPS2D: 40 S ribosomal protein S2-3; RPS9b: 40 S ribosomal protein S9b; RPS9c: 40S ribosomal protein S9c; RPS9d: 40S ribosomal protein S9d; SBT1.7: Subtilisin-like protease SBT1.7; SBT3.5: Subtilisin-like protease SBT3.5; SC34: 60S ribosomal protein L10-1; SCP41: Peptidase S10; SCPL50.1: Serine carboxypeptidase-like 50; SCPL50.2: Serine carboxypeptidase 50; SCPL51: Serine carboxypeptidase-like 51; SEN102: Zingipain-2-like; SPN1: Serpin-ZXA; SYP132: Syntaxin-132; TAX10: 3'-N-debenzoyl-2'-deoxyTaxol N-benzoyltransferase; TBCLD15: TBC1 domain family member 15; TIM9: Mitochondrial import inner membrane translocase subunit; TON1B: Protein TONNEAU 1b; TON1C: Protein TONNEAU 1c; TOR1: Microtubule-associated protein SPIRAL2; TR1: Tropinone reductase; TRXH: Thioredoxin H1; TTL: Uric acid degradation bifunctional protein; TUBA1: Tubulin alpha-1; TUBB1: Tubulin beta-1; TUBB3: Tubulin beta-3; TUBB5: Tubulin beta-5; TUBB6: Tubulin beta-6; UOX: Uricase; VPE2: Vacuolarprocessing enzyme; VPS2.1: Vacuolar protein sorting-associated protein 2.1; WWOX: Retinol dehydrogenase 12; XCP2: Xylem cysteine proteinase 2; XTH22: Xyloglucan endotransglucosylase 22; XTH8: Xyloglucan endotransglycosylase 8; YKT61: VAMP-like protein YKT61

\section{Acknowledgments}

The National Key R\&D Program of China (no. 2018YFD0300306) supported this study.

\section{Authors' Contributions}

$W Z$, and $W X$ and JG designed the research plan; XW, JY and XZ performed most of the experiments; $C B, D H, S L$ and $X Z$ recorded most of the experiments data; $\mathbf{W X}$ wrote the paper. All authors read and approved the final manuscript.

\section{Funding}

The National Key R\&D Program of China (no. 2018YFD0300306) supported this study.

\section{Availability of Data and Materials}

The mass spectrometry proteomics data have been deposited to the ProteomeXchange Consortium (http://proteomecentral.proteomexchange. org) via the PRIDE partner repository with the dataset identifier PXD016653. After the data have been published, the access connection in ProteomeXchange will be: http://proteomecentral.proteomexchange.org/cgi/ GetDataset? ID = PXD016653.

\section{Ethics Approval and Consent to Participate}

Not applicable.

\section{Consent for Publication}

Not applicable.

\section{Competing Interests}

The authors declare that they have no competing interests.

\section{Author details}

${ }^{1}$ Key Laboratory of Northern Japonica Rice Genetics and Breeding, Ministry of Education and Liaoning Province, Key Laboratory of Northeast Rice Biology and Genetics and Breeding, Ministry of Agriculture, Rice Research Institute of Shenyang Agricultural University, Shenyang 110866, China. ${ }^{2}$ Graduate School of Agricultural Science, Tohoku University, Sendai 981-8555, Japan.

Received: 6 November 2019 Accepted: 6 December 2020

Published online: 07 January 2021

\section{References}

Bellegarde F, Maghiaoui A, Boucherez J, Krouk G, Lejay L, Bach L, Gojon A, Martin A (2019) The chromatin factor HNI9 and ELONGATED HYPOCOTYL5 maintain ROS homeostasis under high nitrogen provision. Plant Physiol 180(1):582-592 
Cai H, Lu Y, Xie W, Zhu T, Lian X (2012) Transcriptome response to nitrogen starvation in rice. J Biosci 37:731-747

Chinpongpanich A, Limruengroj K, Phean-o-pas S, Limpaseni T, Buaboocha T (2012) Expression analysis of calmodulin and calmodulin-like genes from rice, Oryza sativa L. BMC Res Notes 5(1):625

Curci PL, Cigliano RA, Zuluaga DL, Janni M, Sanseverino W, Sonnante G (2017) Transcriptomic response of durum wheat to nitrogen starvation. Sci Rep 7: 1176

Foster CE, Martin TM, Pauly M (2010) Comprehensive compositional analysis of plant cell walls (lignocellulosic biomass) part I: lignin. J Vis Exp 37:e1745

Francisco RH, Shane MW, López-Bucio J (2015) Nutritional regulation of root development. Wiley Interdiscip Rev Dev Biol 4(4):431-443

Godfray HC, Beddington JR, Crute IR, Haddad L, Lawrence D, Muir JF, Pretty J, Robinson S, Thomas SM, Toulmin C (2010) Food security: the challenge of feeding 9 billion people. Science 327:812-818

Gutiérrez RA (2012) Systems biology for enhanced plant nitrogen nutrition. Science 336:1673-1675

Hakeem KR, Ahmad A, lqbal M, Gucel S, Ozturk M (2011) Nitrogen-efficient rice cultivars can reduce nitrate pollution. Environ Sci Pollut Res 18:1184-1193

Hao J, Guo H, Shi XN, Wang Y, Wan QH, Song YB, Zhang L, Dong M, Shen CJ (2017) Comparative proteomic analyses of two Taxus species (Taxus $X$ media and Taxus mairei) reveals variations in the metabolisms associated with paclitaxel and other metabolites. Plant Cell Physiol 58:1878-1890

Hua L, Wang DR, Tan LB, Fu YC, Liu FX, Xiao LT, Zhu ZF, Fu Q, Sun XY, Gu P, Cai HW, McCouch SR, Sun CQ (2015) LABA1, a domestication gene associated with long, barbed awns in wild rice. Plant Cell 27:1875-1888

Ju C, Buresh RJ, Wang Z, Zhang H, Liu L, Yang J, Zhang J (2015) Root and shoot traits for rice varieties with higher grain yield and higher nitrogen use efficiency at lower nitrogen rates application. Field Crop Res 175:47-55

Lee D, Polisensky DH, Braam J (2005) Genome-wide identification of touch- and darkness-regulated Arabidopsis genes: a focus on calmodulin-like and XTH genes. New Phytol 165:429-444

Lescano Cl, Martini C, González CA, Desimone M (2016) Allantoin accumulation mediated by allantoinase downregulation and ransport by ureide permease 5 confers salt stress tolerance to Arabidopsis plants. Plant Mol Biol 91(4-5): $581-595$

Li Y, Yang X, Ren B, Shen Q, Guo S (2012) Why nitrogen use efficiency decreases under high nitrogen supply in rice (Oryza sativa L.) seedlings. J Plant Growth Regul 31:47-52

Liu X, Zhang Y, Han W, Tang A, Shen J, Cui Z, Vitousek P, Erisman JW, Coulding K, Christie P, Fangmeier A, Zhang F (2013) Enhanced nitrogen deposition over China. Nature 494:459-462

Luo J, Zhou J, Li H, Shi W, Polle A, Lu M, Sun X, Luo ZB (2015) Global poplar root and leaf transcriptomes reveal links between growth and stress responses under nitrogen starvation and excess. Tree Physiol 35(12):1283-1302

Lynch JP (2013) Steep, cheap and deep: an ideotype to optimize water and N acquisition by maize root systems. Ann Bot 112:347-357

Marschner H (1995) Mineral nutrition of higher plants, 2nd edn. Academic, London

Meng F, Xiang D, Zhu J, Li Y, Mao C (2019) Molecular mechanisms of root development in Rice. Rice 12(1):1

Mi GH, Chen FJ, Wu QP, Lai NW, Yuan LX, Zhang FS (2010) Ideotype root architecture for efficient nitrogen acquisition by maize in intensive cropping systems. Sci China-Life Sci 53:1369-1373

Qin L, Walk TC, Han P, Chen L, Zhang S, Li Y, Hu X, Xie L, Yang Y, Liu J, Lu X, Yu C, Tian J, Shaff JE, Kochian LV, Liao X, Liao H (2019) Adaption of roots to nitrogen deficiency revealed by 3D quantification and proteomic analysis. Plant Physiol 179(1):329-347

Saengwilai P, Tian X, Lynch JP (2014) Low crown root number enhances nitrogen acquisition from low-nitrogen soils in maize. Plant Physiol 166:581-589

Subodh S, Amitha SV, Saurabh C, Punit T, Sureshkumar V, Manju R, Pranab M (2018) Transcriptome analysis of two Rice varieties contrasting for nitrogen use efficiency under chronic $\mathrm{N}$ starvation reveals differences in chloroplast and starch metabolism-related genes. Genes 9:206

Sun HY, Qian Q, Wu K, Luo JJ, Wang SS, Zhang CW, Ma YF, Liu Q, Huang XZ, Yuan QB, Han RX, Zhao M, Dong GJ, Guo LB, Zhu XD, Gou ZH, Wang W, Wu YJ, Lin HX, Fu XD (2014) Heterotrimeric G proteins regulate nitrogen-use efficiency in rice. Nat Genet 46(2):652-656

Tabuchi M, Sugiyama K, Ishiyama K, Inoue E, Sato T, Takahashi H, Yamaya T (2005) Severe reduction in growth rate and grain filling of rice mutants lacking osgs 1;1, a cytosolic glutamine synthetase1;1. Plant J 42(5):641-651
Tian D, Yang L, Chen Z, Chen Z, Wang F, Zhou Y, Luo Y, Yang L, Chen S (2018a) Proteomic analysis of the defense response to Magnaporthe oryzae in rice harboring the blast resistance gene Piz-t. Rice 11(1):47

Tian L, Shi S, Nasir F, Chang C, Li W, Tran LSP, Tian C (2018b) Comparative analysis of the root transcriptomes of cultivated and wild rice varieties in response to Magnaporthe oryzae infection revealed both common and species-specific pathogen responses. Rice 11(1):26

Turek I, Wheeler Jl, Gehring C, Irving HR, Marondedze C (2015) Quantitative proteome changes in Arabidopsis thaliana suspensioncultured cells in response to plant natriuretic peptides. Data in Brief 4:336-343

Walch-liu P (2006) Nitrogen regulation of root branching. Ann Bot 97(5):875-881

Wang J, Song K, Sun L, Qin Q, Sun Y, Pan J, Xue Y (2019) Morphological and Transcriptome analysis of wheat seedlings response to low nitrogen stress. Plants 8:98

Wang XC, Chang LL, Tong Z, Wang DY, Yin Q, Wang D, Jin X, Yang Q, Wang LM, Sun Y, Huang QX, Guo AP, Peng M (2016) Proteomics profiling reveals carbohydrate metabolic enzymes and 14-3-3 proteins play important roles for starch accumulation during cassava root tuberization. Sci Rep-UK 6:19643

Wang ZQ, Xu XY, Gong QQ, Xie C, Fan W, Yang JL, Lin QS, Zheng SJ (2014) Root proteome of rice studied by iTRAQ provides integrated insight into aluminum stress tolerance mechanisms in plants. J Proteome 98:189-205

Wasteneys GO, Yang Z (2004) New views on the plant cytoskeleton. Plant Physiol 136:3884-3891

Wu WM, Cheng SH (2014) Root genetic research, an opportunity and challenge to rice improvement. Field Crops Res 165:111-124

Xin W, Zhang L, Zhang W, Gao J, Yi J, Zhen X, Du M, Zhao Y, Cheng L (2019b) An integrated analysis of the Rice Transcriptome and Metabolome reveals root growth regulation mechanisms in response to nitrogen availability. Int J Mol Sci 20(23):5893

Xin W, Zhang L, Zhang W, Gao J, Yi J, Zhen X, Li Z, Zhao Y, Peng C, Zhao C (2019a) An integrated analysis of the Rice Transcriptome and Metabolome reveals differential regulation of carbon and nitrogen metabolism in response to nitrogen availability. Int J Mol Sci 20(9):2349

Xu G, Fan X, Miller AJ (2012) Plant nitrogen assimilation and use efficiency. Annu Rev Plant Biol 63:153-182

Yang W, Yoon J, Choi H, Fan Y, Chen R, An G (2015) Transcriptome analysis of nitrogen -starvation-responsive genes in rice. BMC Plant Biol 15:31

Yang X, Nian J, Xie Q, Feng J, Zhang F, Jing H, Zhang J, Dong G, Liang Y, Peng J (2016) Rice Ferredoxin-dependent glutamate synthase regulates nitrogencarbon Metabolomes and is genetically differentiated between japonica and indica subspecies. Mol Plant 9:1520-1534

Zhang G, Ye J, Jia Y, Zhang L, Song X (2018) iTRAQ-based proteomics analyses of sterile/fertile anthers from a thermo-sensitive cytoplasmic male-sterile wheat with Aegilops kotschyi cytoplasm. Int J Mol Sci 19(5):1344

Zhang H, Xue Y, Wang Z, Yang J, Zhang J (2009) An alternate wetting and moderate soil drying regime improves root and shoot growth in rice. Crop Sci 49:2246-2260

Zhou D, Yang Y, Zhang J, Jiang F, Craft E, Thannhauser TW, Kochian LV, Liu J (2017) Quantitative iTRAQ proteomics revealed possible roles for antioxidant proteins in sorghum aluminum tolerance. Front Plant Sci 7:2043

\section{Publisher's Note}

Springer Nature remains neutral with regard to jurisdictional claims in published maps and institutional affiliations. 